Feature Article

\title{
A Tool for Sustainability: A Case for Biogas in Sri Lanka
}

\author{
A. A. P. de Alwis*1 \\ ${ }^{*}$ Professor of Chemical and Process Engineering, Department of Chemical and Process Engineering \\ University of Moratuwa, Moratuwa, Sri Lanka
}

\section{Introduction}

Sri Lanka at present oscillates between an energy crisis and an economic crisis now entwined as a result of costly private power purchase agreements based on thermal power aggravated by rising fuel prices. The country indeed can claim to be the only country in the region to provide uninterrupted power to the consumer but the situation at present had been realized at an enormous cost. The loss for the Ceylon Electricity Board (CEB) in the last year had been stated to be Rs. 53 billion, no small amount which could have been well used elsewhere. The power purchases are soft options and at the heart of operations lies the process of generation. On the agriculture front, the government is engaged in a costly subsidy operation with respect to the provision of fertiliser while the responsible scientists lament about the serious degradation in soil quality as provision of soil amendments etc. are not taking place. This is resulting in lower yields but with higher costs of production. There is a serious opportunity for organic matter to be used up in this area. The write up is to be courageous in thinking about biogas based power generation in a big way while realising additional benefits which will really give meaning to the statement sustainable processes in national economic management and development.

The interest in renewable energy systems is continuing across the globe in all types of economies and Sri Lanka is no exception. However, in the context of Sri Lanka Biogas can said to be the 'Cinderella' among all renewable as yet the attention that it justly deserves due to its 'beautiful potential' has not materialised. The longer the country delays this the costlier it would be for any implementation. While many express the benefits and the potential of biogas, influential publications in Sri Lanka fails to allocate even up to a paragraph on this versatile technology option. As summarised in Figure 1 from Chanakya (2002) the versatility of biogas stems from its ability to address any emerging issue of the time. The biogas initially appeared in supporting public health in developing economies and quickly migrated to addressing energy security for the poor under the energy crisis of seventies. Today it appears to be a front line option in addressing the threat pose by climate change. Biogas as a combination of methane and carbon dioxide provide a natural gas mix in working to produce nanomaterials in the emerging nanotechnology revolution which in turn will lead to a new material platform (Vamathevan, 2011). Natural gas along with carbon dioxide had been experimented upon by many to realise 'syngas' from which various energy and material pathways can be derived and in biogas one realises both together from waste materials by biological action. The captivity by 'Cinderella' still eludes the planner and the policy maker.

*Correspondence: ajith@uom.lk

Tel: +94 112650301 , Fax: +94112650622

ISSN 2235-9370 Print / ISSN 2235-9362 Online (C2012 University of Sri Jayewardenepura 


\section{Biogas in Sri Lanka}

Sri Lanka has experience with biogas systems for a long period though the results can said to be of mixed quality. This has resulted in biogas being relegated to a small scale energy delivery opportunity at best and do not find any mention in influential publications. The opportunity with biogas as an option in energy delivery systems was identified a long time ago as a feasible and desirable for Sri Lanka again perhaps with the same background thought as in this case Sri Lanka was seen as a country with a significant segment of population struggling for energy. This resulted in a program of the United Nations adopting the resolution as Colombo Declaration way back in April 1974 after a meeting in Colombo, which stated that one of the urgent priorities in the region is Energy. Subsequently, a project for the development of Anaerobic Digestion throughout Asia was approved in November 1974 which was championed by a Pakistani nuclear scientist - Dr Usmani who was with UNEP at the time. However, much of Asia had really not benefited from developments in this area and energy shortage problems are quite common within the region. Even the flagship project started in Sri Lanka under UNEP's Rural Energy Project, the Pattiyapola Center in the Hambantota district failed to fulfil its expectations though it demonstrated the potential. The Pattiyapola scheme was to be a Rural Energy Research Project Experimental Station (Barnett et al, 1978) and was planned as one per each continent. de Alwis (2001) discusses this project in some detail.

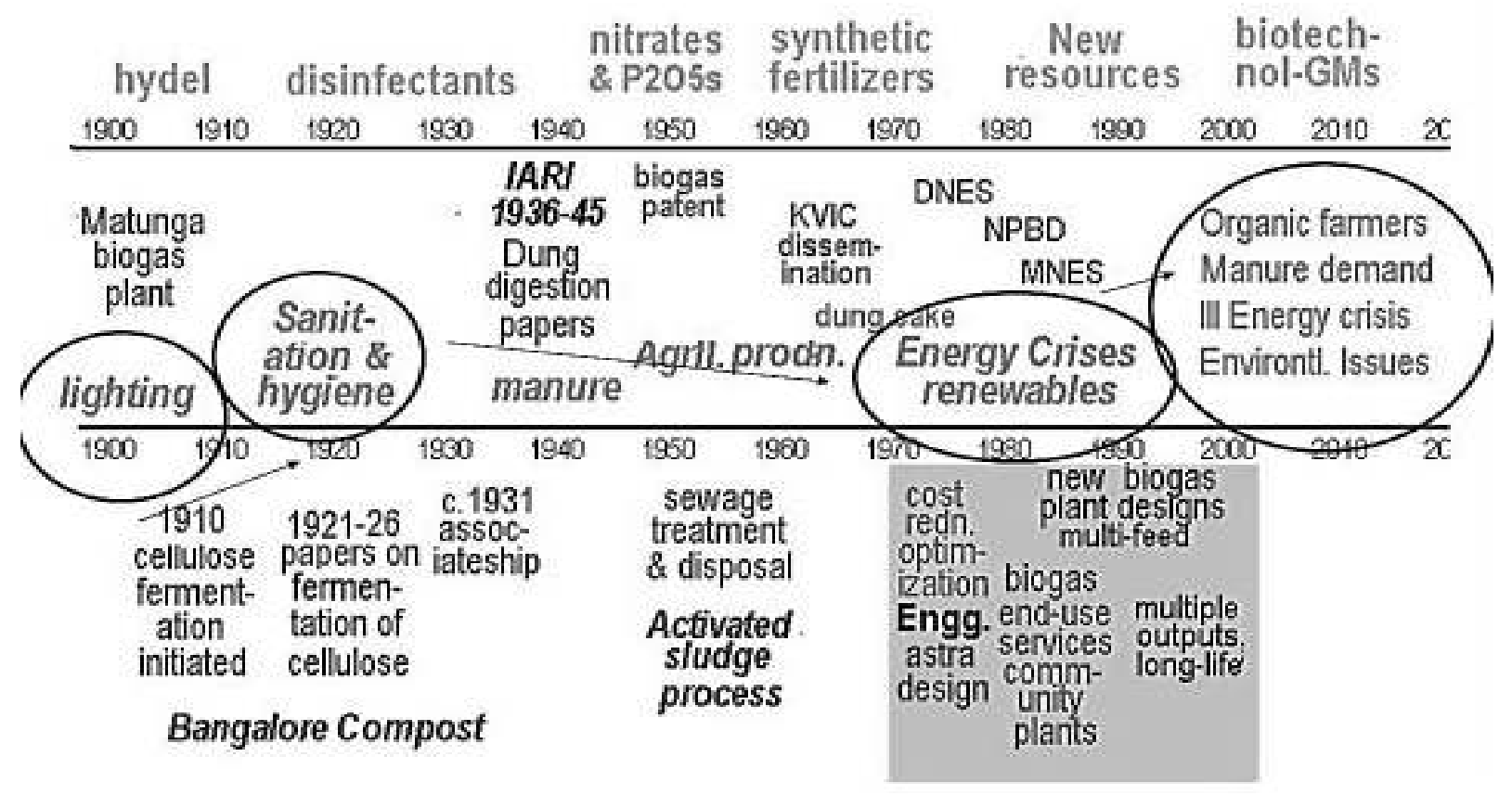

Figure 1: Biogas potential across multiple issues facing the world

It is unlikely that biogas can serve as a cure for all energy problems of Sri Lanka but this can be classified as a triple benefit technology and can challenge any other renewable energy technology to show similar capabilities. Sri Lanka should have sufficient energy, produced in an efficient manner, and in this biogas technologies can play a vital role as a steady state renewable energy supply operating in a decentralised manner. It can serve as an efficient environmental management tool. With some individuals it can play the role of improving their quality of life while reducing the economic burden. For the farming community it will serve as a useful 'fertiliser' supply using their own waste products. Much foreign exchange can be saved and external energy dependence reduced. Improved technological competitiveness and competence resulting from this type of strategy will benefit other areas as well. It 
is indeed a pity that in Sri Lanka planners is oblivious to these opportunities with one technology and continues to pursue different pathways in fulfilling requirements in three different ways. A truly sustainable option is ignored. EU has shown in the light of climate change mitigation studies that Biogas provides the best 'well-to-wheel' fuel and this is significant. Ministry of Science and Technology supported study demonstrated the applicability in a local context with the use of a better gas digester system and further work is awaited (Kularathne et al, 2008, Dilyana et al., 2010). Figure 2 indicates the UOM Pilot project and potential is indeed worth thinking about.

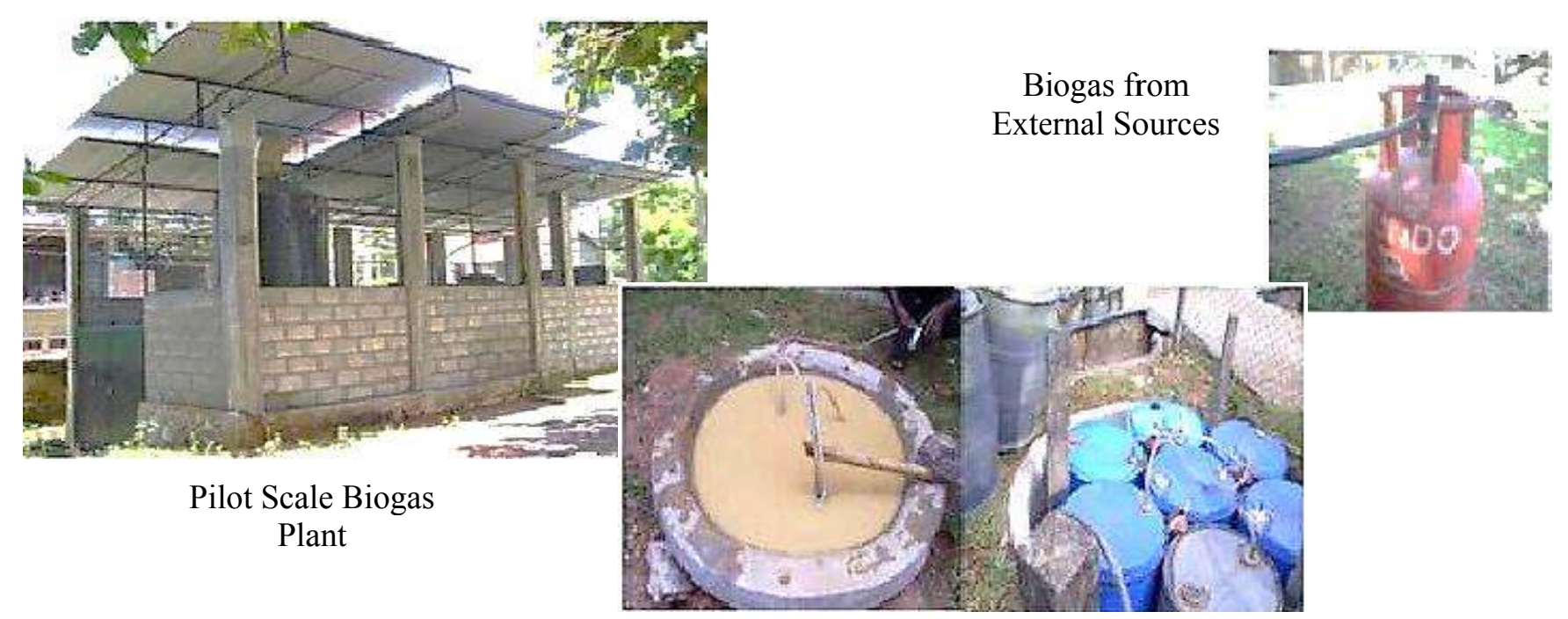

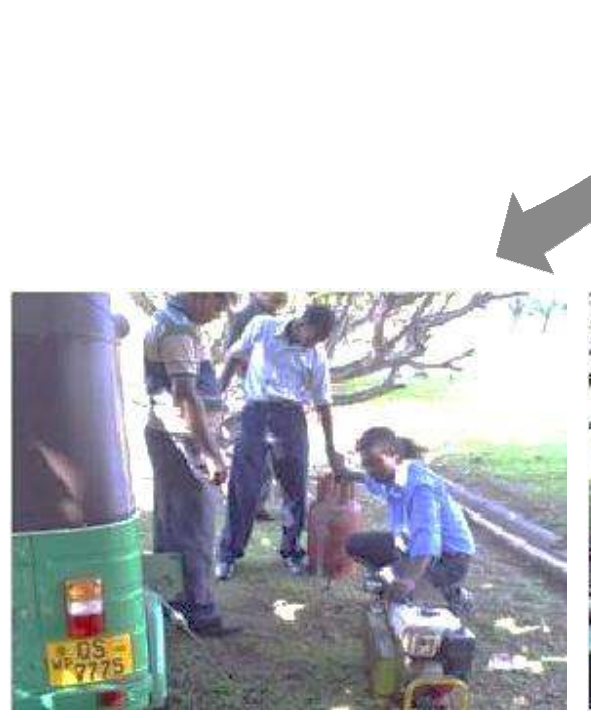

Biogas feeding to the Three-Wheeler

Dry Batch Pit

\section{Biogas}

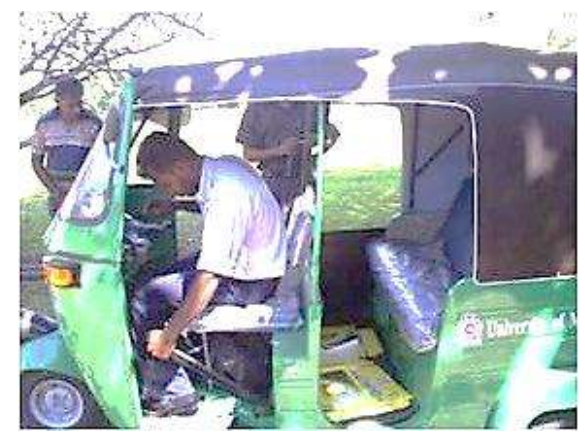

First Ignition

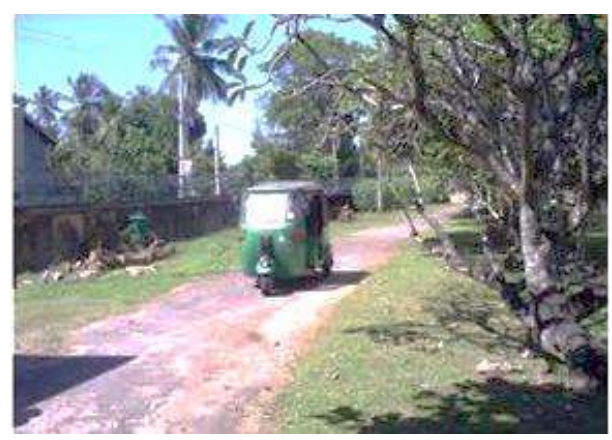

First Run

Figure 2: Pilot scale demonstration of biogas as a transport fuel at University of Moratuwa

\section{Triple Issues and aligning Triple Benefits through Biogas}

- Sri Lanka lacks conventional sources of energy and as fossil fuel supplies dry out the purchase costs are bound to rise and the country should be ready with technology options to serve energy needs of both stationary and mobile sectors. As the standards of living improve and per capita income changes the demand made on energy will increase and these need to be always factored in. At present the nation is 
totally ill-equipped to handle such an eventuality and are extremely susceptible to price and demand fluctuations. It is expected that industrialization to take us towards the status of a newly industrialised country. However, the existing industries face severe problems from their waste management practices and in turn lack a stable and a sufficient energy supply. The latter aspect is hindering industrial growth in several parts of the country. The industrial sector of Sri Lanka can hardly said to be in any way competitive.

- The environmental degradation in urban and semi-urban areas due to the generated solid waste is quite acute and is a growing problem with urbanization and population growth. We have not yet addressed this issue in a technically sound manner and the results from mismanagement is to be seen everywhere. It is important to realise that having vehicles to collect and transport for a final dumping site away from main stream view is not the final solution to the problem. The sewage generated is piped away to ocean outfalls in the City of Colombo without any treatment. The individual septic systems are managed through gully bowser services when capacity exceeds or percolates slowly to the landmass with time. There is no recovery of energy from this potential waste organic scheme and contributes adversely to groundwater and water pollution. Sea disposal is not being encouraged and contamination of fish can prove to be quite a problem as time passes. While country has to consider HAACP certification for fish exports local population may have to be satisfied with sub standard feed having no other option.

- Agriculture sector has many complaints due to rising fertiliser cost which has a direct effect on the profitability and the cost of produce. The escalating costs directly affect the consumer, which has severe economic consequences as this sector provides employment to a significant percentage. It is known that the consumer in Sri Lanka on average spends about $50-60 \%$ of his income on food and this is totally unacceptable. One way of reducing the burden is having a different source of 'fertiliser' input available. One major import to the country is urea and is heavily subsidised and this is mainly provide $\mathrm{N}$ to crops such as paddy.

If one looks at these three problems and the wet biomass processing it is evident that the country stands to benefit from the triple advantages offered by the biogas option.

- Energy Source - biogas is a clean energy source and can be enriched to natural gas quality

- Environmental Management - Solid and liquid waste conversion to biogas removes the organic waste burden

- Fertiliser / Soil Conditioner - from the residue left after anaerobic digestion and has enriched nitrogen in case of manure treatment

It is indeed sad that the country has not exploited a technology, which is fast becoming quite a mature technology elsewhere (in Germany in 2010, 2291 MWe (12.6\% of renewable electricity) of national electricity was met through biogas and decentralised systems are quite common) to the best advantage of our nation. The diversion of the organic fraction of the solid waste (OFMSW) will entail work upstream which will help realising more resources to recycling as well as the technology will have a mechanical step in the front end of the technology.

Biogas extraction and use has become a vibrant industrial technology that is now finding applications due to variety of reasons in developed countries. Some of these are essentially the problems faced today by developing countries as well. It is simply not possible for the developing economies to ignore the problems and seek solutions in another way;

- Global Climate Change Issues: Uncontrolled methane emissions - as emitted from solid and liquid wastes of organic composition under anaerobic condition - are not acceptable today as methane is a powerful greenhouse gas $(\mathrm{GHG})$. Thus control of these emissions is essential from a climate change point of view. The solution that has been forwarded is the capture of this gas and utilise it via 
combustion thus converting it to $\mathrm{CO}_{2}$ and obtaining energy as well. In addition land filling of municipal solid waste practiced by many developed economies now has brought in legislation prohibiting organic waste being land filled. This is again due to the methane emissions as landfill methane capture is not the most efficient and emissions can be quite problematic.

- Conventional energy sources are depleting: The world has realised that there is only a finite time and that the time available is also short before conventional fuel resource base is depleted. Thus the need to develop renewable energy resources have intensified and it is important to have proven, reliable and commercially viable energy systems available when the crunch occurs. It is not possible to develop new ways once the crisis is well set in. Developed nations are locked in finding technological pathways and with renewables it is important to work with available resource bases.

- As a tool for sustainable development: Today the emphasis is on sustainable development and both the way energy is used and the management of the environment have been given equal consideration. The potential of a good soil conditioner from biogas generation is another positive aspect. In satisfying these triple needs, biogas option provides a neat clean development mechanism.

\section{Creating the Environment for Biogas in Sri Lanka}

The potential is clear but the paper does not provide hard numbers to clinch the case. There is a need to accept the common sense view that is sweeping many external industrialised nations. In such economies there is a need for migration as different systems are already in place and there is no incentive for immediate implementations. However the situation is different for Sri Lanka. Thus policies must evolve to simultaneously support right hardware which then can lead to significant developments. At this juncture with regard to renewable energy systems application of conventional benefit-cost calculations may not mean much.

A Biogas system's value as an environmental management technique is a key factor in utilising the technique across sectors such as the urban environment, industrial waste treatment and livestock and agriculture waste management facilities. The utilisation of a biogas system within these sectors will remove these places at least partially from the main energy supply chain. It is for this partial displacement that the country should be planning for initially.

The promotion of biogas systems, based on raw materials such as animal waste and straw, have been largely targeted towards the rural household sector. Despite practise since the 1970's the success rate of these ventures has been low for many reasons. The findings of the national survey on biogas systems has been summarised in de Alwis (2002). In developing countries, the promotion of biogas technology has been mainly directed towards this sector. In developed countries, the emphasis has been different.

In developed economies, biogas technology has also been utilised successfully but in sectors such as industrial and urban waste treatment. Quite large systems have come into commercial operation and cities such as Stockholm are planning to switch to compressed biomethane for its transport fleet. These systems, known as high-rate units, will have higher initial technical inputs and necessitate different management systems. The type of digester systems used in these are high-rate units. High rate digestion is an improved mixed-phase digestion process in which the digester contents are maintained at $35-37^{\circ} \mathrm{C}$ and are completely mixed, enhancing digestibility of the substrate. Most European reactors are operating at thermophilic range for higher efficiencies and as these countries face winters it is important for them to have more controlled digester systems. Sri Lanka can avoid thermophilic systems as the ambient mesophilic conditions are quite acceptable for hi-rate operations. There will be a requirement in slightly larger sizing as a result of lower rates of kinetics but this is not significant. 


\section{A multi-step Strategy (adopted from de Alwis, 2001)}

It is evident that today there is a conducive climate both from policy perspective and in demonstrated technology for utilising biogas energy systems. However, to realise the biogas potential in Sri Lanka, several important developments are necessary to what is currently available. These should form essential steps in an overall strategy.

(a) Awareness of the problem (in terms of both energy and environment) and the consequent need for innovative solutions. There has to be policy initiatives in promoting these options available. However, the awareness should be more focused and detailed and it should be across the entire stakeholder group. One should move away from introducing basics (these activities definitely cannot be totally phased out) to more specific and detailed introductions. Most of the times at present presentations on biogas is not going beyond simple introductions - What? How and Why? advantages and disadvantages etc.

For an industry it is stated that normally 5M's are required - Material, Men, Machinery, Money and Management. It is important to understand that the anaerobic digestion as an industry has to have one more $\mathrm{M}$ - Microorganisms. The proper process understanding is essential. This has been ignored so far in the South. The South has been pre-occupied with a 'Container' approach - always looking at varying the container as a way of reducing costs. The North has understood and implement the 'Process' approach. Today there is much more understanding of the microbial consortia responsible for anaerobic digestion across the multi-step process and improving efficiencies are possible.

(b) It is quite important that research and data collection is carried out with the specific aim of biogas development. A more structured and a coordinated approach in research and development work is necessary and also data gathering had to be improved. These efforts will benefit many other developments as well. Technology and the non-availability of industrial capital are the strongest drawbacks the country faces in developing renewables of this nature. One should identify the core engineering capabilities required in the promotion and the development and the quality aspects required in winning the hearts and the minds of the consumers. Basic instrumentation in monitoring and analysers required in $R \& D$ are lacking and these need to be remedied. Virtually connecting across research groups in Sri Lanka and with external networking much progress can be made. It is interesting to note that IndianDRDO (Defence research and Development Organisation)has claimed to successfully demonstrated biogas even in hilly colder regions today with working continuously on process development.

(c) Adoption of biogas systems in sewage handling (in the urban sector) should be promoted and developed. It is difficult at present to imagine sewerage systems coming into use widely. Thus integrating functionally and aesthetically biogas systems into waste management and energy generation to household systems is necessary. Wherever installing sewerage systems anaerobic digestion should form part of the overall objective of such systems. Decentralised anaerobic systems can well come in urban sewage management. Developing local area sewage networks is possible as truly to benefit with energy extraction a reasonable quantity of waste need to be present.

(d) Development of appropriate end-use mechanisms at both individual and institutional levels are necessary. The use of biogas for cooking may not meet with everyone's satisfaction in the urban/rural environments. With miniaturised equipment available biogas units with gas cleaning may be even connected to household level transport fuel supply opportunities. Household fuel cell systems are becoming available with biogas as the fuel feedstock. This demonstrates the extent to which different high end energy systems are coming into play today.

(e) Development of convenient digestion systems (the concrete/ brick masonry types are inappropriate as flexible or convenient systems). At household level one should look at incorporating a biogas system into the initial architectural planning. This type of popularisation using different materials is quite 
important in developing flexible systems for use. The manufacturing and fabricating capability should exist within the country. The necessary controls and instrumentation capabilities should also be built into these units designed for various utilisation contexts. A recent plastic biogas system developed locally is today available off-the-shelf for consumers and is a welcome development which can be further developed.

(f) Development of national standards for biogas systems at various levels of utilisation. SLSI (Sri Lanka Standards Institute) is the relevant body. Here information can be obtained and developed from Indian and other European standards for different types of systems, appliances etc. The first SLS standard for biogas systems for home based systems had been completed and launched (SLS 1292:2006). The remaining two standards in the first phase are to cover the Farm and Institutional systems and Industry based systems. Lack of internal experiences is preventing the development of these standards at present. The developments in the latter two should be expedited.

(g) Emergence of private entrepreneurs with the ability to install and support biogas systems. For industrial systems it is possible to look at making the technology currently available externally, such as BIOENERGY (from Biomechanics), BIMA (Entech), ANAMET (AC-Biotechnics), ArrowBio (ArrowEcology), BIOFAR (Degremont), HYAN (Gore \& Storrie), DRANCO (Organic Waste Systems) under licence to the local market. The market and monitoring mechanisms practised in Nepal are of interest for small systems in Sri Lanka. The Indian National Master Plan for biogas (2000-2005) offers a learning opportunity in technology transfer, adaptation and indigisation. A comprehensive review of biogas systems in the European Union is provided in Nynes and Thomas S. (1998). It is important to note that KOMPOGAS (Axpo Kompogas Ltd.) a plug flow biogas system won the 2002 Energy Globe award (the world awards for sustainability) and is another well-developed system. There is also the option of starting small and scaling up Hi-rate biogas systems locally as the process mechanisms are known and it is not mandatory to source external process systems. Scaling-up the system as developed by Kularathne (2011) is quite feasible and this is the pathway to be taken when building internal capacity for technology.

(h) Since food and agro industries have the potential to dominate the Sri Lankan production and manufacturing sector, one can always envisage that if successful use of biogas systems is demonstrated, our emerging industries will stand to benefit from the knowledge base that will be readily available within the country. Successes at the industrial sector level may in turn encourage the small scale use of low-rate systems at societal level.

(i) More enlightened financing schemes should be set in place. Indian IREDA is an example. Indians are utilising GEF (Global Environmental Facility) funds quite effectively in the development of biogas energy systems and there is a separate Government ministry for non-conventional energy sources. Thailand's VSPP (Very Small Power Producer) scheme (<1MWe) supported significant biogas systems development. Sri Lankan banks should be more enterprising and adopt and adapt different schemes for funding projects falling into these categories. It is important to realise that the present climate for renewable development is not exactly even a one of transition as the oil prices are at quite low levels and thus the technologies that have been developed have the edge over the developing technologies. However, the critical need for country's development cannot be decided solely on the basis of a cost in Rupees and cents and the government together with banks should understand this. Any transition requires state to support and this support is evident within the world's strongest economies.

There are many technical options available for biogas energy systems though falling into few select categories in terms of technical definitions (i.e. low-rate, high-rate, fully mixed, plug flow etc). Most projects -if not all- today are guided by the conventional Cost-Benefit (CCB) analysis to guide investment decisions. The simple logic being, if the benefits of a project exceed the costs, the investments should be undertaken. As can be seen some thrust in development of biogas has occurred 
due to environmental reasons. These aspects are difficult if not impossible to identify and quantified and nor do they have proper market values. Though non-market Environmental valuation Techniques are (EVT) are available to carry out an extended benefit cost analysis perhaps it is much easier to utilise common sense and national policies of importance to devise mechanisms for development of these technologies. Thus government intervention is necessary. This is true and applicable in developed countries as well as seen in United Kingdom, Australia and European Union. Germany has given quite favourable feed-in-tariff rates to encourage biogas electricity schemes which led to significant developments.

(j) The most important factor is that the biogas production system should be considered in totality, rather than as a digester and a particular raw material - the Systems Approach. Each aspect of the system should be equally supported (Figure 3).

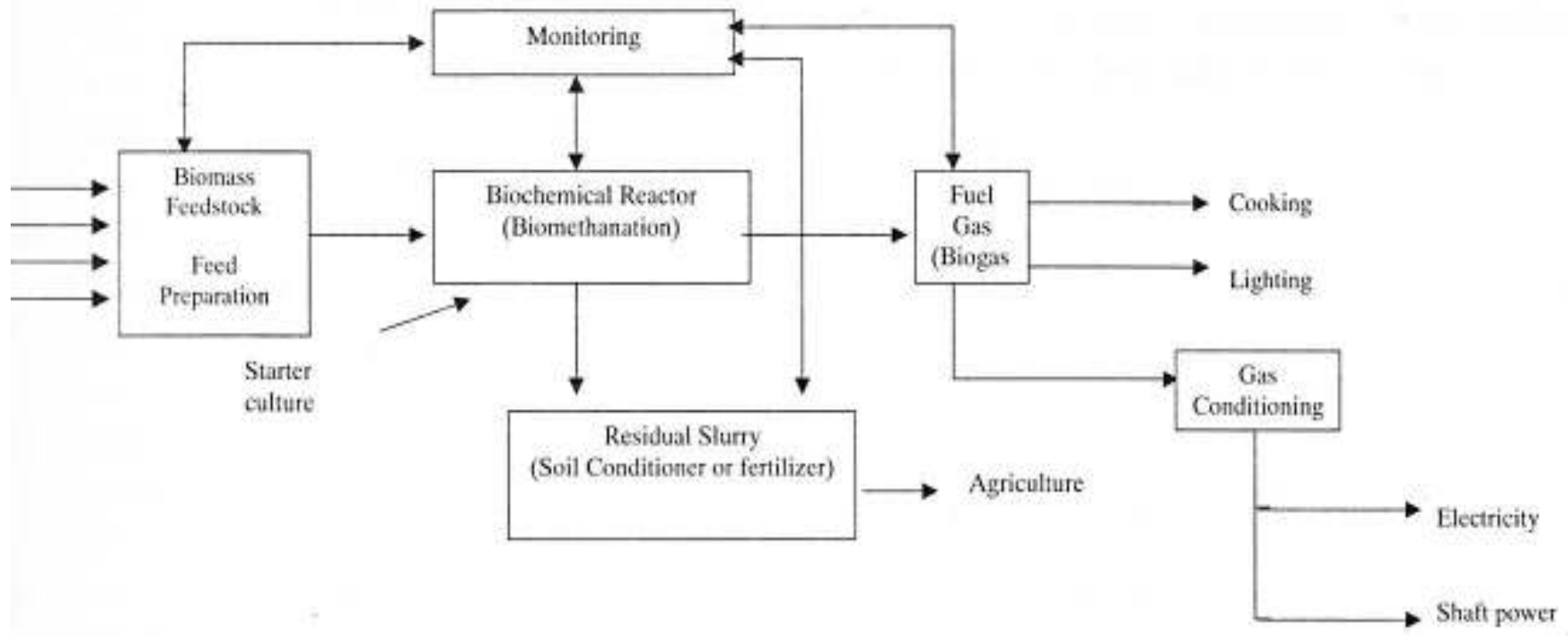

Figure 3: Understanding the whole 'System' for successful utilization

\section{Conclusion}

The proposed strategy is to promote biogas systems from a top down approach, i.e. from large/medium scale units to small scale units or from industrial/institutional systems to individual units. Perhaps in the agriculture sector a more mixed approach is necessary. The biogas can and will be successful if there is enough emphasis on commercialisation and with the promotion of technologies through market mechanisms. The steps indicated should be the essential elements in the implementation strategy and should be in place to serve all levels of users. Sri Lankan policy planner should move away from looking at the biogas option mainly as a life-enhancing tool for the rural villager in a developing economy! and also from the view point that 'high' end technology is not for us!!

It is unlikely and more of a certainty that biogas cannot serve as a cure for all energy, environmental and soil fertility problems of Sri Lanka. Sri Lanka should have sufficient energy, produced in an efficient manner, and in this biogas technologies can play a vital role as a steady state renewable energy supply operating in a decentralised form. Much foreign exchange can be saved and external energy dependence reduced. Improved technological competitiveness and competence resulting from this type of strategy will benefit other areas of our economy as well. 
One may conclude that there has never been a more important and an opportune time to develop viable renewable clean sustainable process technology system for Sri Lanka. The implementation process is challenging yet this is an opportunity that should not be wasted away.

\section{References}

Barnett A., Pyle L. and Subramanian SK. 1978, Biogas Technology in the Third World: A multidisciplinary review, IDRC Publication.

Chanakya N. Hoysala. 2002. Indian Institute of Science, Bangalore, Personal Communication

de Alwis AAP, Solid Waste Management in Sri Lanka: A Country Perspective in Solid Waste Management, Grover VI, Guha BK, Hogland W, McRae SG (eds), Oxford \& IBH Publishing Co. Pvt Ltd. Pp 203-233, 2000.

de Alwis, A.A.P. 2002, Biogas - A review of Sri Lanka's performance with a renewable energy technology, Energy for Sustainable Development, Vol VI, No 1, pp 30-37.

de Alwis, A.A.P. 2002. Industrial biomethanation practices for decentralized energy from waste: Options for Sri Lanka in Recovering Energy from Waste: various aspects, Grover VI, Grover VK and Hogland W (eds), Science Publishers Enfield USA, pp 151-165, 2002

de Alwis, A.A.P. 2002. Sri Lanka: Its industry and challenges in the face of climate change, Chapter 18 in Climate Change: Five years after Kyoto, Grover VI and Grover VK (eds), Science Publishers, USA, pp 377-395, 2004.

de Alwis, A.A.P. 2001. Study on the potential of Biogas in Sri Lanka, Renewable energy options - study 2, ITDG-South Asia publication.

Dilyana K.W.N., Kularathne, M.A.D.I.C., Rathnasiri, P.G., Joseph, P.G. and de Alwis, A.A.P. 2010. Optimisation of an anaerobic co-digestion process and use of biomethane as a transport fuel, Procs of the National Energy Symposiym, BMICH, Colombo pp 29-36.

Evans, G. 2005. Biowaste and Biological Waste Treatment, James \& James (Science Pub.) Ltd., London.

Kularathne, M.A.D.I.C. 2011. Development of a Pilot Plant to demonstrate Biogas as a Transport Fuel, MSc Thesis, Dept of Chemical and Process Engineering, University of Moratuwa.

Kularatna, M.A.D.I.C., de Alwis, A.A.P., and Rathnasiri, P. G. 2008. Review on Upgrading and Application of Biogas as a Vehicle Fuel, Procs of $14^{\text {th }}$ ERU Annual Symposium, Oct $15^{\text {th }}$, Faculty of Engineering, University of Moratuwa pp 36-37.

Mitzlaff, K. 1988.Engines for Biogas: Theory, modifications, economic operation, Friedr. Vieweg \& Sohn Braunschweig/Wiesbaden, Germany.

Nynes and Thomas S. 1998.Biogas from waste and wastewater treatment, CD from James \& James UK. SLSI, 2006. Code of Practice for Design and Construction of Biogas Systems Part 1 - Domestic Biogas Systems, SLS 1292: 2006.

Vamathevan, K. 2011. The Development of the Process to synthesize carbon nanotubes from biogas, MSc Thesis, Dept of Chemical and Process Engineering, University of Moratuwa. 